Scientific Visualization, 2020, volume 12, number 2, pages 84 - 97, DOI: 10.26583/sv.12.2.07

\title{
The ArcGis 3D visualization of geological data and mine shaft operation within the analytical information system "Construction - Geological Environment"
}

\author{
P.A. Krasilnikov ${ }^{1}$ \\ Perm State University \\ ${ }^{1}$ ORCID: 0000-0002-0602-6143, chisp07@gmail.com
}

\begin{abstract}
$\underline{\text { Abstract }}$
Emergency situations occurring at the complex engineering constructions from time to time could be avoided due to complete and reliable information on the construction and the geological stratum, which is the base of the facility or its environment. The author believes that technical services monitoring the construction requires theconstant update on analytical information models of the system "Construction-Geological Environment", which contains technical characteristics of engineering constructions and indicators of the geological structure.

This type of model is an analogue of the BIM- modeling and can provide technical services specialists with reliable and efficient information on all stages of the construction life cycle. The obligatory model element is $3 \mathrm{D}$ data visualization, that allows controlling the adopted design decisions at a new level. Thus changes can be made in proper time as errors are detected.

The article proposes an approach to 3 Dvisualization of a complex technical engineering construction (mine shaft) located inside the geological environment by means of ArcGis. The approach proposed has been implemented on the example of sinking two mine shafts in the Verkhnekamskoye potassium-magnesium salts deposit. The article presents the main modeling results visualized both in a two-dimensional and $3 \mathrm{D}$ mode at certain points of time. The application of the ArcGis environment gives the possibility of both conducting a spatial analysis of the available data and preparing the presentation material in a dynamic mode (animation).
\end{abstract}

Keywords: geographical information system, modeling, data visualization, engineeringgeological environment, construction.

\section{Introduction}

In recent years, no one doubts the assertion that information is one of the most valuable resources. The lack of efficient, reliable and complete information about an engineering and technical object and its geological environment can often lead to emergency situations, information about which often appears in mass media. In recent years, a number of design organizations have been switching to the BIM technology for designing buildings and constructions because it makes possible to obtain actual information about the condition of an operated facility at any stage of its life cycle. On its basis, a well-grounded management decision is made ensuring its further safe operation. However, any construction does not hang "in the air", but rests upon or inside an array of rocks (mines, subways, underground parking lots, etc.). Therefore, the awareness of the technical characteristics of the construction is not considered to be sufficient. For the safety of operation it is necessary to create analytical information systems (AIS) of the construction containing not only its characteristics but also the parameters of the geological environment. Thus, there is need to create analytical information 
systems of the construction including its characteristics and parameters of the geological environment, which may also be changed over time.

Modeling the system "Construction - Geological Environment" is the task of a specialist in the field of engineering geology, who can make forecasts of affecting various factors on the basis of this model. In the work [11], the authors pointed out that due to visualization (visual presentation of information), a geological engineer can evaluate the holistic picture of the researched sphere to constitute new patterns or to determine inaccuracies arisen.

Visual presentation of geological data can be two-dimensional and 3D. Two-dimensional visualization of engineering and geological data is usually represented by sections, well columns and thematic maps. 3D visualization is more often used in solving some more complicated tasks, constructing volumetric geological bodies associated with calculating reserves and designing mine workings.

The most popular software products that provide two-dimensional visualization of geological and engineering-geological data are automatic design systems (ADS), such as AutoCAD, Credo, Geocad, SurfCad and Pipeline. These engineering and geological programs are used mainly for the preparation of the geological columns and sections. The application of geological information systems (ArcGis, Mapinfo, QGis, GIS-panorama, etc.) in engineering geology is aimed at creating maps for various purposes.

For $3 \mathrm{D}$ visualization of geological data, almost all the above mentioned software products can be used, which are referred both to CAD and geological information systems. However, in order to create and display complex geological bodies and solve $3 \mathrm{D}$ tasks, the packages of $3 \mathrm{D}$ geological modeling (Leapfroq, Micromine, Surpac, etc.) are the most suitable ones. Thus, in the work [13], the Leapfrog software product is the main tool for making a geological model and data visualization. However, all of them are rather complicated, expensive and require additional specialized training.

The geological information systems are sufficient for modeling and visualizing the data on the natural-technical system "Construction - Geological Environment". Thus, in the work [10], the results of the engineering-geological investigations are presented being visualized by ArcView. The GIS technologies, the ArcGIS software product is represented in the work [12] as the main tool of the synthesis and $3 \mathrm{D}$ visualization.

In this article, the solution is proposed to create an analytical information system that provides the $3 \mathrm{D}$ data visualization on the basis of the GIS systems. The tools to work with $3 \mathrm{D}$ graphs are implemented quite well within such systems and make possible to monitor the design decisions adopted at the new level and to make changes in proper time when errors are detected on the example of sinking shafts.

\section{Recognition of the problem and research topicality}

In many cases a deposit opening is carried out by vertical shafts during the underground mining. They open access to working horizons in the shortest way, load elevation along them is the most convenient, and the expenses are the lowest. When the depth of the development is large, the deposit opening by means of vertical shafts is the only possible way. Approximately 95\% of vertical shafts in hard rocks are concreted and have a circular cross section of 3 to 9 meters in the diameter [5].

Sinking the vertical shafts, which consumes $40-50 \%$ of the duration of the total construction and up to $15 \%$ of the total capital expenditures is one of the most complicated and laborintensive jobs in constructing a mine. The shaft is the main opening tool of a mine, and if it is disrupted, the entire mining enterprise may break off its work. The duration of the shaft s work depends on the correct choice of the construction support having sufficient loadbearing capacity. Therefore, higher designing requirements are made to the calculations of the construction support [1]. The next important step is the implementation and observation of the design decisions adopted in full and with high quality. 
Because of the lack of the sufficient information significant complications may arise in the course of the shaft construction in the areas with difficult geological mining conditions and increasing depths.

V.V. Tarasov and V.S. Pestrikova in their work [2] collected and brought together the available information about the emergencies that occurred when sinking the mine shafts in the Verkhnekamskoye deposit of potassium and magnesium salts. According to their opinion, the main reasons for the occurrence of the accidents are: the incompletion of reliable information about the aquifers intersected by the shafts, and their hydro chemical characteristics; the presence of previously unrevealed natural cracks in the ground wall; the presence of nonfrozen rocks in the ice-rock enclosure; the damage of freezing columns; the inconsistency of construction works with the design decisions adopted.

The causes of the emergencies mentioned above could be excluded by up-to-date analytical information system which is capable of monitoring the quality of the construction works and make changes into the project in proper time when new data appear.

For example, when sinking a mine shaft before installing tubing support, the sketches of the excavation ground walls is carried out to fix some lithological differences, existing cracks and water occurrences. Based on this new information, efficient adjustment of design decisions is possible. Moreover, such type of the analytical information system as well as the application of the methods of $3 \mathrm{D}$ numerical simulation is capable of calculating the formation of an icerock enclosure in the plan and depth at a definite point of time. This information can give a well-grounded understanding of the degree of freezing of the ground mass. Therefore, creating the systems of this kind is an urgent task.

\section{Selection and substantiation of software}

The literature review on this issue showed that similar work on creating a shaft database is underway. For example, in the laboratory of aerology and thermophysics of the Mining Institute of the Ural Branch of the Russian Academy of Sciences, an analytical information system "Shaft passport" was created, which is designated for:

- monitoring the current state of the shaft;

- creating a database on the construction, operation and repair of mine shafts;

- analytical data processing (speed of movement of lifting vessels, profiling) [6].

According to the reports, this database works only in the reamer mode and the information in the plan and visualization in the $3 \mathrm{D}$ environment is not available in it.

In addition, the company Sight-Power implements a set of modules designated for solving problems arising in the course of constructing mine shafts called Shaft Builder.

The obtained information during the shaft sinking is unique, and thus is worth further use. The created analytical information system of the mine shaft is to be a part of the geological mining system of the enterprise. Only in this case, it is possible to maximize the use of both the current and the obtained information. In this case, it is appropriate to avoid purchasing a new type of software to solve a one-time task, but to use that software at a subsoil user`s disposal that was used for the creation of the geological mining system of the enterprise. The ArcGis program is at the disposal of all the enterprises developing the Verkhnekamskoye deposit. In addition, they also use the «Geoconstructor» software module [9] for maintaining geological information, which implements communication with the GIS systems. Therefore, to create an analytical information system, the ESRI software product ArcGis was used.

Geographic information systems are ideally suited for creating the database of this kind. Different researchers repeatedly described their advantages when working with spatial information $[7,8]$.

The maintenance of the GIS-based system will allow to:

- improve work planning;

- reveal inaccuracies and errors in the existing project;

- implement coordination of the work performed and the design decisions; 
- reduce decision-making time in case of emergency;

- use efficiently the unique material on the geological structure of the fixed space in the area of the mine shaft.

\section{Analytical information system of sinking a mine shaft}

The system based on the ArcGis 10.5 software product for the Talitsky site of the VKMKS was worked out by the author of the article. For its effective work, in addition to a standard set of tools presented in the ArcGis software product, it was necessary to create a specialized computational software module (Addin) that implements the generation of reamers for a given center, a radius (cylindrical coordinate system) and a projection of the shaft elements onto a reamer. This software module was created by the specialists of the company LLC «Inform $++»$. The software is able to collapse the data obtained on the reamer into a $3 \mathrm{D}$ model. Recalculation of the coordinates from the cylindrical reamer into the geographic ones and vice versa also does not cause difficulties.

The created analytical information system considerably differs from the traditional geological, surveying or mining GIS projects. It requires a specialized geographic information base, the GIS project of the mine shaft as the basis, which includes the following categories of the data corresponding to the stages of the work:

1. The results of drilling the controlled shafts and freezing wells:

- geological structure;

- description of the laboratory data of the core investigations;

- geophysical and hydro geological data;

- inclinometry data of freezing wells and calculations of the thickness of the ice-rock enclosure.

2. Design decisions:

- project of tubing support (seams, tubings, filling and grouting plugs);

- $\quad$ project of zatyubing support (supporting crowns, keycranz, tamponages curtain);

- project of the interfaces between the shaft and working horizons.

3. Actual data in the process of sinking:

- sketches of the shaft walls and sampling points, including mapping of cracks, folds, water inflows and other complications in the structure of the rock mass;

- executive survey of the sinking process and fixing the shaft;

- complications during the operation of the mine shaft (deformation of conductors and support, water occurrence, data on the performed repair work);

- other types of data involved directly or indirectly in assessing the condition of the shaft (results of repeated investigations, geophysical data).

According to the tasks to be solved, on the basis of the available data, three basic types are created and constantly supported - a plan (top view), a wall reamer (combined with sections) and a $3 \mathrm{D}$ model convolution. A set of layers with the necessary attributive information is created for each view.

The first two types (plan, reamer) exist in one project, by means of creating the two frames of data that makes possible to pass efficiently from the work in the plan to the work in the reamer (Fig. 1).

$3 \mathrm{D}$ visualization of data is also implemented by means of software ArcGis and ArcScene application. Thus, the analytical information system is represented by the database in the format .mdb and two files of the project with expanding .sxd and .mxd in order to be able to work on the plane and in a $3 \mathrm{D}$ way, respectively.

The information stored in the plan is done in real coordinate system that allows to carry out the synthesis of heterogeneous data with the minimum labor input as well as the overlay operations with the information obtained from various sources.

The information stored in the reamer is done in the conditional coordinate system, where absolute elevations of objects in the Baltic elevation system are placed on the y-axis, 
whereas on the $\mathrm{x}$-axis there is orientation to the cardinal points. Moreover, the position of north is indicated by $0-$ value and the maximum value 30,568 corresponds to the position of north too. This is because the project draft radius of the shaft is equal to $4,865 \mathrm{~m}$. Thus, the centre of the reamer (on the $\mathrm{x}$-axis the value is 15,284 ) corresponds to the southern cardinal point of the visualized object.

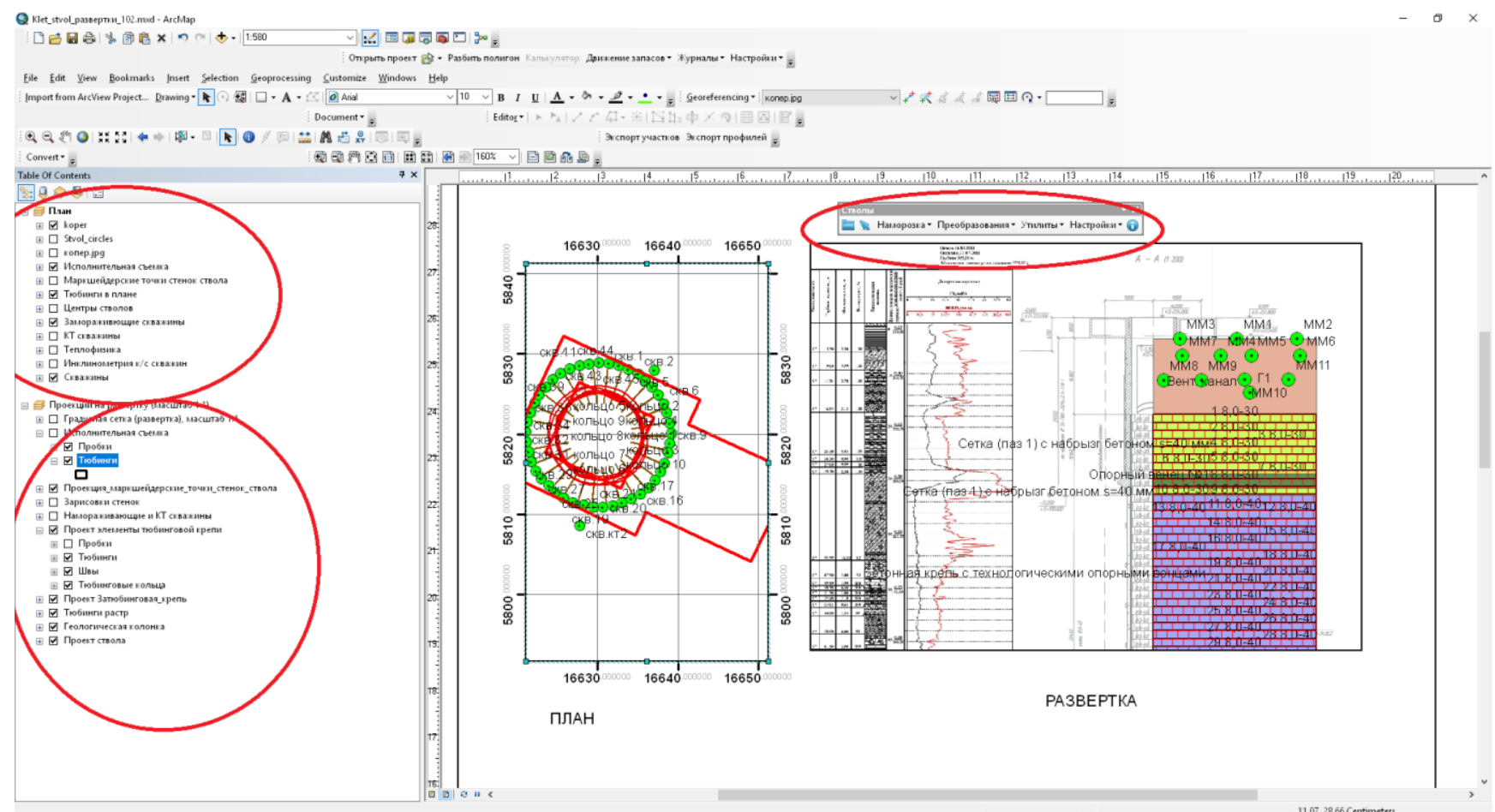

Fig1. The working window of the geoinformation project of the mine shaft sinking

Figure 1 represents the information visualized in the plan and in the reamer on the right side, while the toolbar of the software module "Shafts" is displayed on the top.

The maintenance of the system like this makes possible to compare the data obtained from the results of drilling a control wellbore with the geological description of sinking a shaft.

Except the data mentioned above, the project contains information about the nature of the zatubing space filler and the heads ' (concrete, plastic concrete) power, the presence of possible screens, lock covers and other water blocking things used in the construction of the shaft. It is stored in the attributive tables of the thematic layers. The tiers of reinforcement along with the depth of the shaft to the lithological column, stratigraphic and hydro geological horizons were precisely aligned. There is a full description of the rock mass, opened when sinking the shaft, features of bedding and structure of the geological layers.

According to the executive survey and geological sketches, the exact location of the opened cracks and water occurrences is set and fixed in the project (Fig. 3). Further, these zones will be drawn special attention during defrosting the mass and the shaft operation.

Thus, this project contains all the necessary information about the geological environment and the technical characteristics of the shaft.

The data visualization is carried out by the standard, quite powerful ArcGis tools. There is a wide selection of conventional signs (markers, fillers), and if necessary, you can create your own "unique" map and graph signs using the symbol editing tools. In addition to that, the program possesses a powerful tool for classifying and grouping visualized objects according to the characteristics stored in the relational table, as well as a large set of out-of-frame design elements (coordinate grids, legends of conventional signs, scale, orientation to the cardinal points.). The following are some illustrations of the thematic content of the Gis-project. 


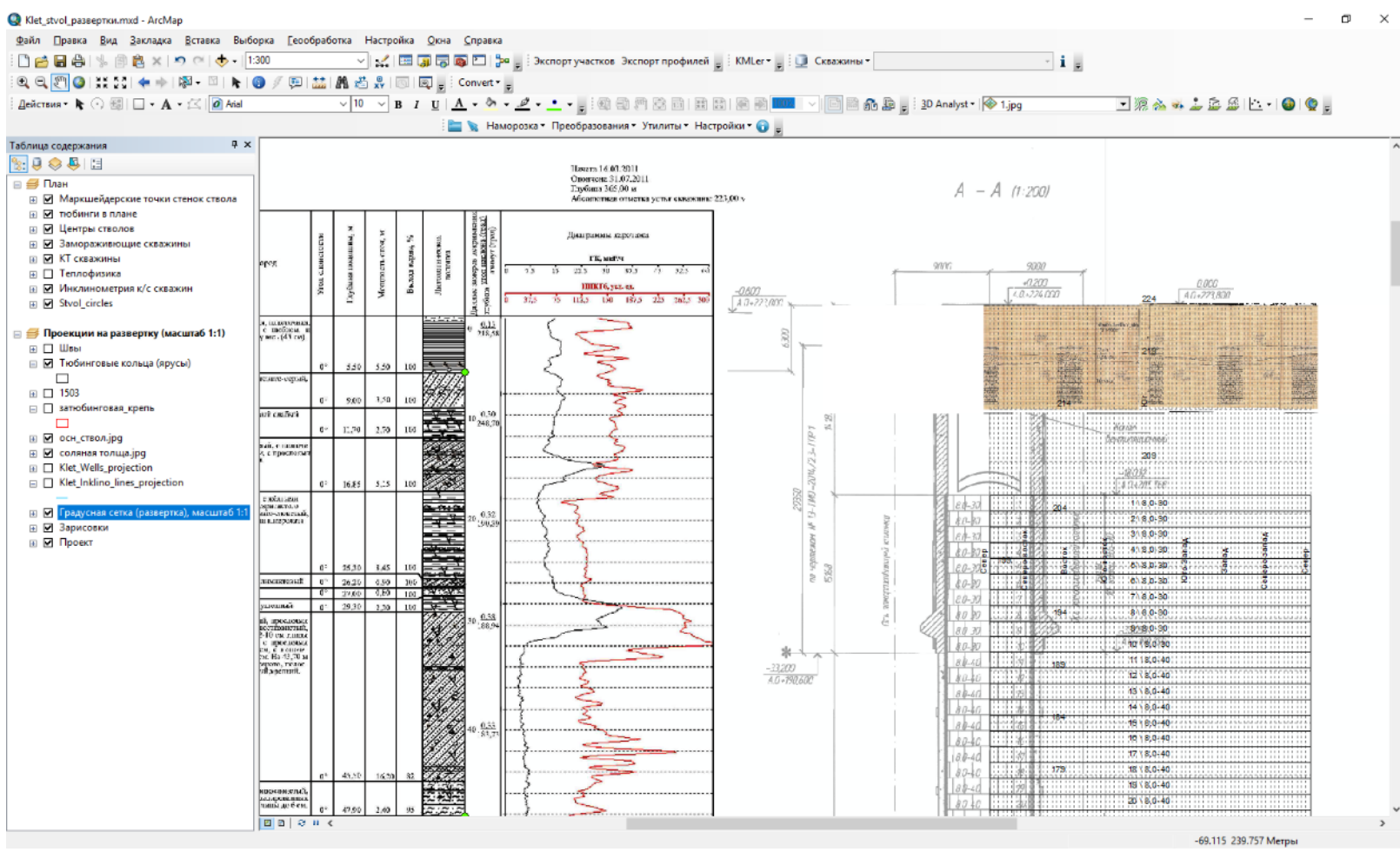

Fig.2. The working project general view of the shaft reamer data storage

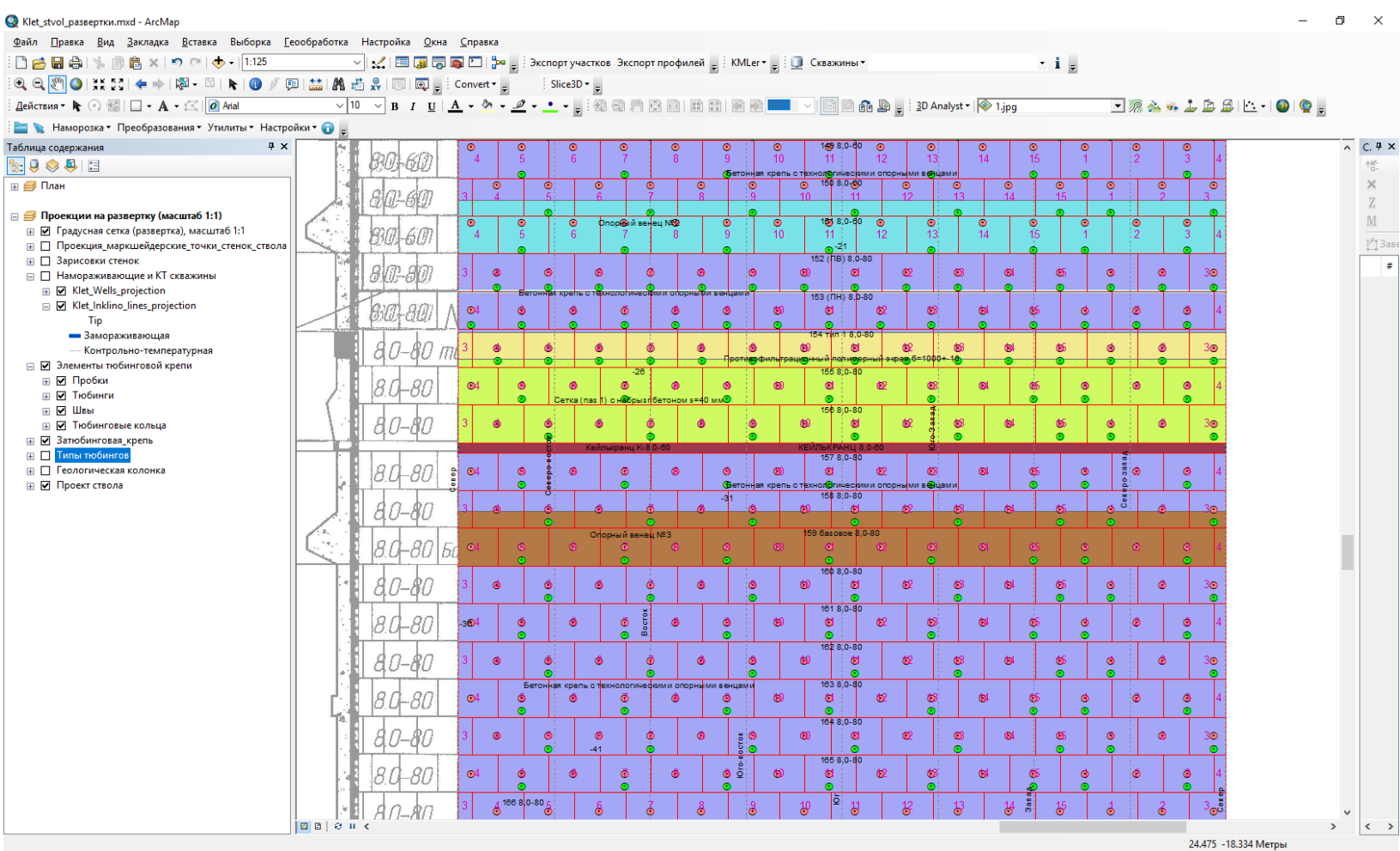

Fig.3. Elements of tubing and zatubing support in the reamer 


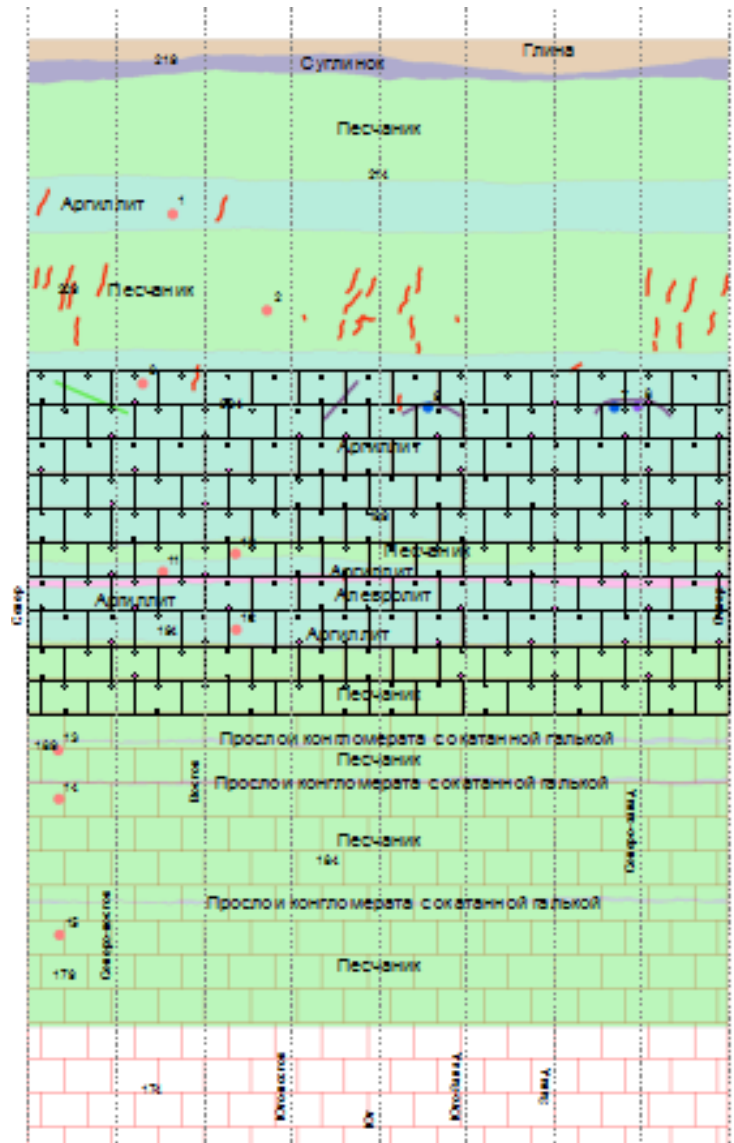

Fig.4.The actual data of geological sketches, fixed tubings and plugs

\section{3D data visualization}

For the $3 \mathrm{D}$ presentation of the input data, it was necessary to obtain $3 \mathrm{D}$ geometry with the preservation of attributive data. To facilitate and accelerate the convertion process of the data from the plane into 3D an additional software module was created. The module makes possible to convolve the flat data into a cylinder for a given center and a radius, and to carry out a reverse operation, if necessary (Fig. 5). An additional toolbar appears in the ArcGis software environment, which makes possible to convolve and project the data with the instructed cylinder diameter and its center. It should be noted that the $3 \mathrm{D}$ geometry obtained is stored in the real coordinate system, which gives the possibility of combining the results obtained with the other data at any time.
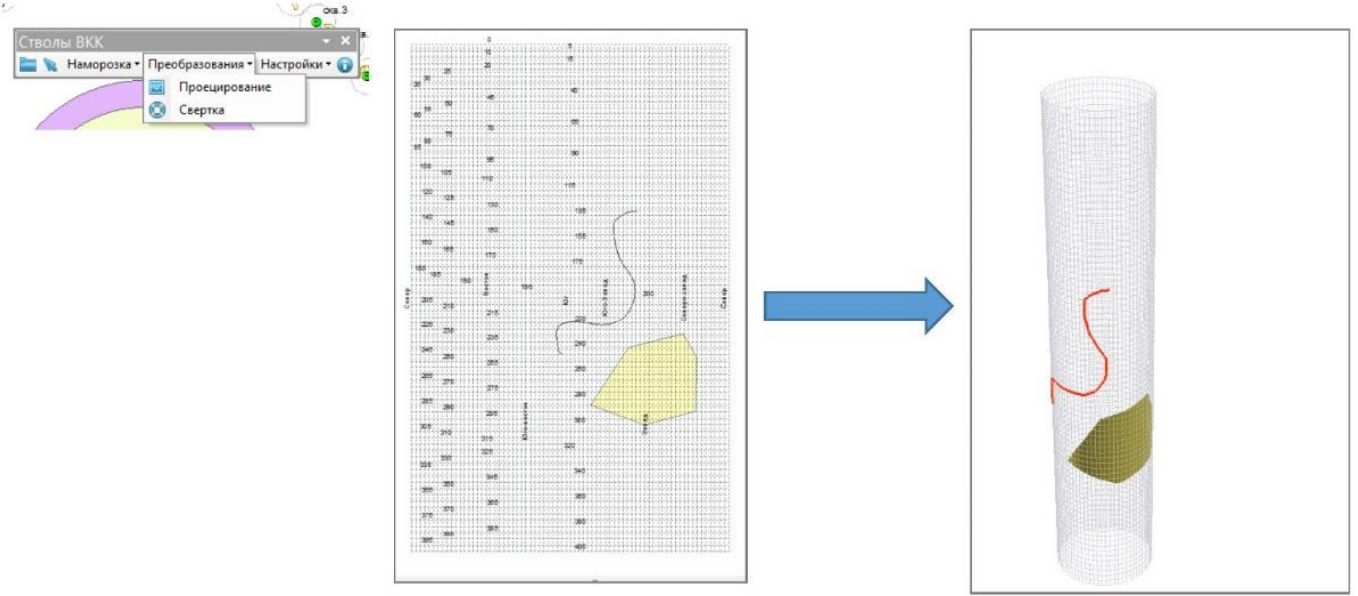

Fig.5. The data convolution into a cylinder 
The visualization of the data obtained is carried out in the ArcScene application, which also possesses a rich set of symbols and fillers, which makes possible to group, classify and reclassify the objects displayed.
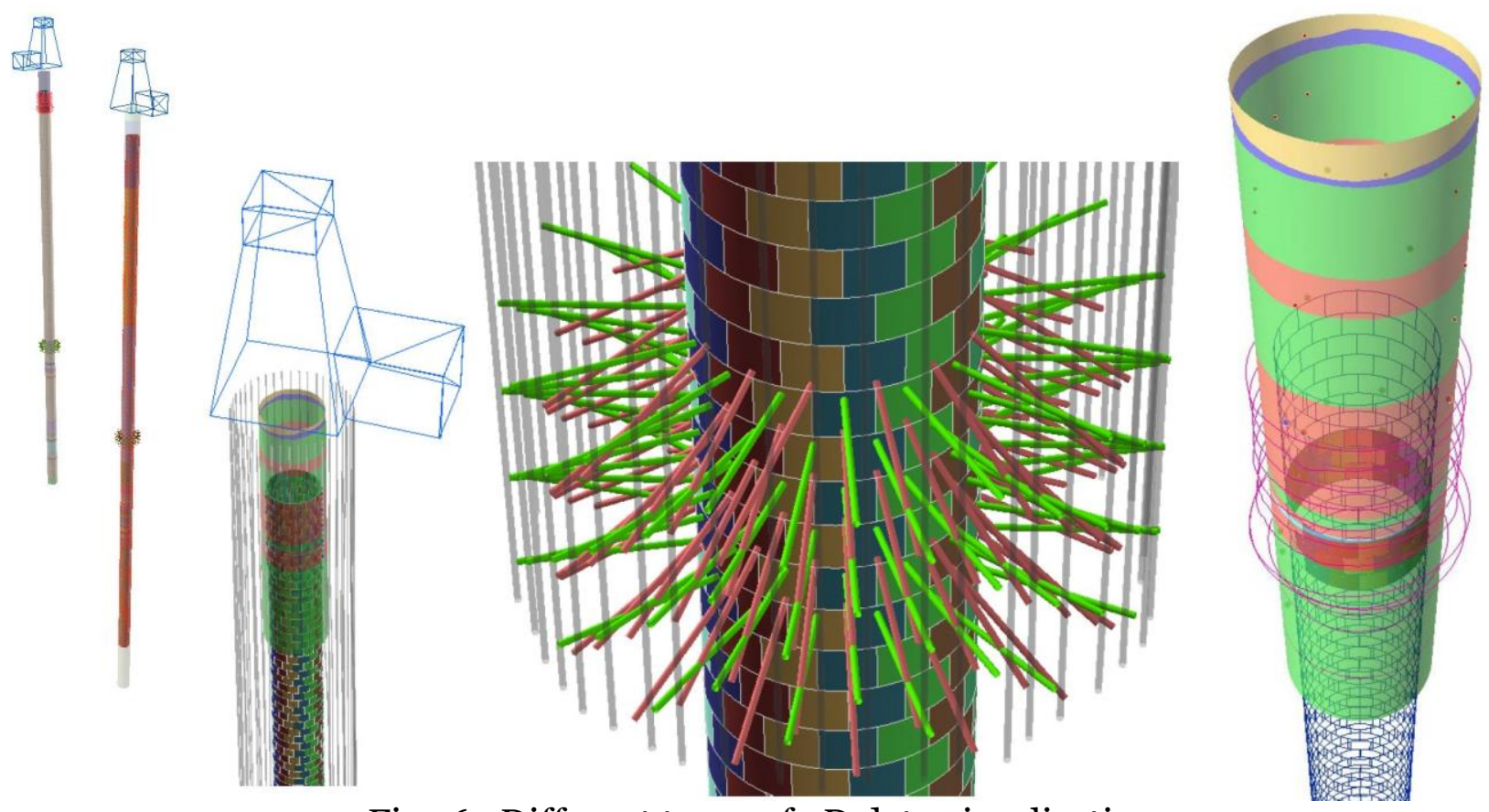

Fig. 6. Different types of $3 \mathrm{D}$ data visualization
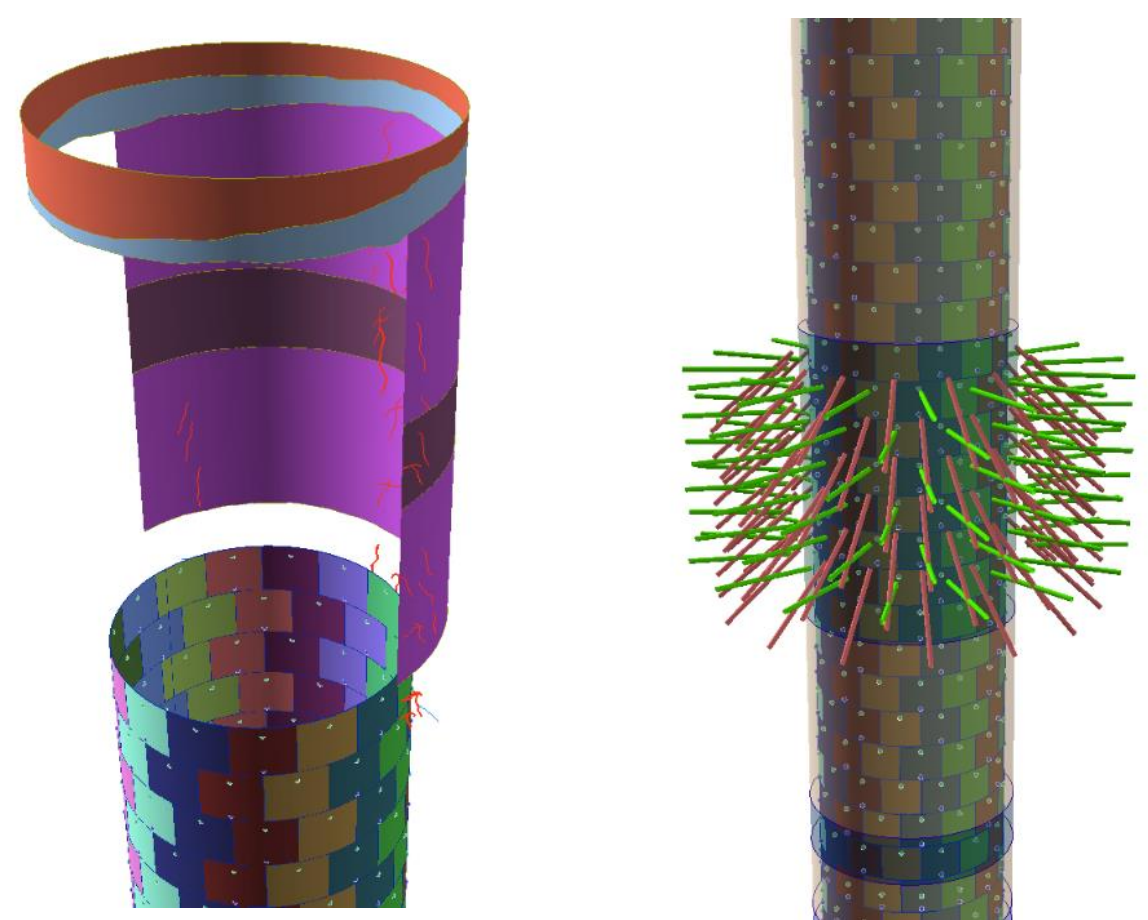

Fig.7. Convolution of geological sketches - on the left, support and water protection elements - on the right 

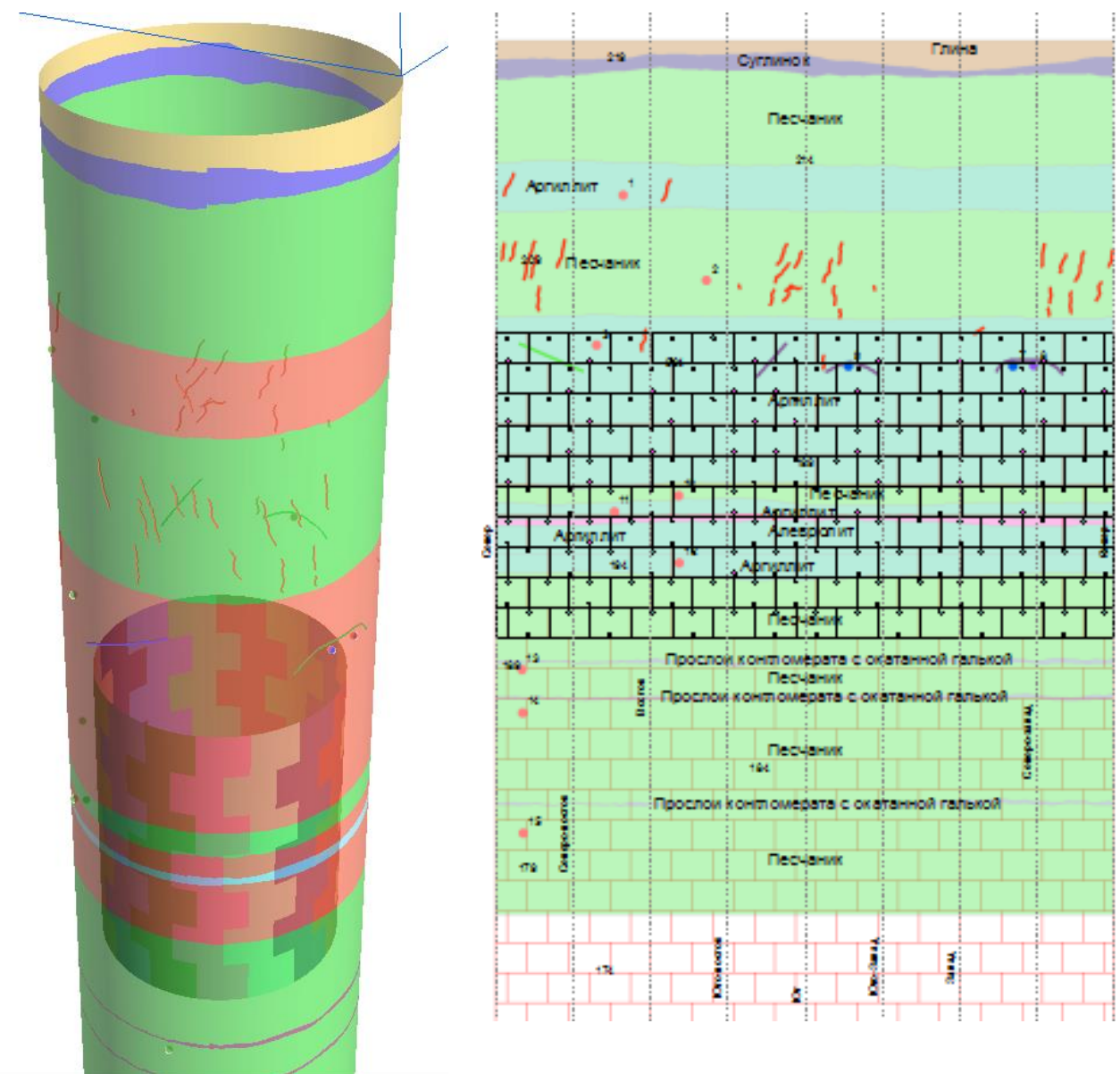

Fig.8. Visualization of cracks in a 3D mode and the reamer

The experience of maintaining the system showed that deviations from the design decisions may happen in the course of sinking the shaft. The types of tubings may be changed and shifted. The degree of the influence of these changes on the safety of the construction operation should be efficiently assessed. Therefore, the required element of the information model like this is the $3 \mathrm{D}$ visualization of the available data for making possible to compare the project data with actual results based on the graphical method (Fig. 9) in order to reveal possible errors and deviations in the project.

For example, when drilling wells of the tamponages curtain, it is necessary to determine if they will cross the axis of the freezing wells, which in this case will result in the depressurization of the freezing columns and will lead to an emergency. The joint display of designed wells and freeze wells is capable of revealing potential risks (Fig. 10). 

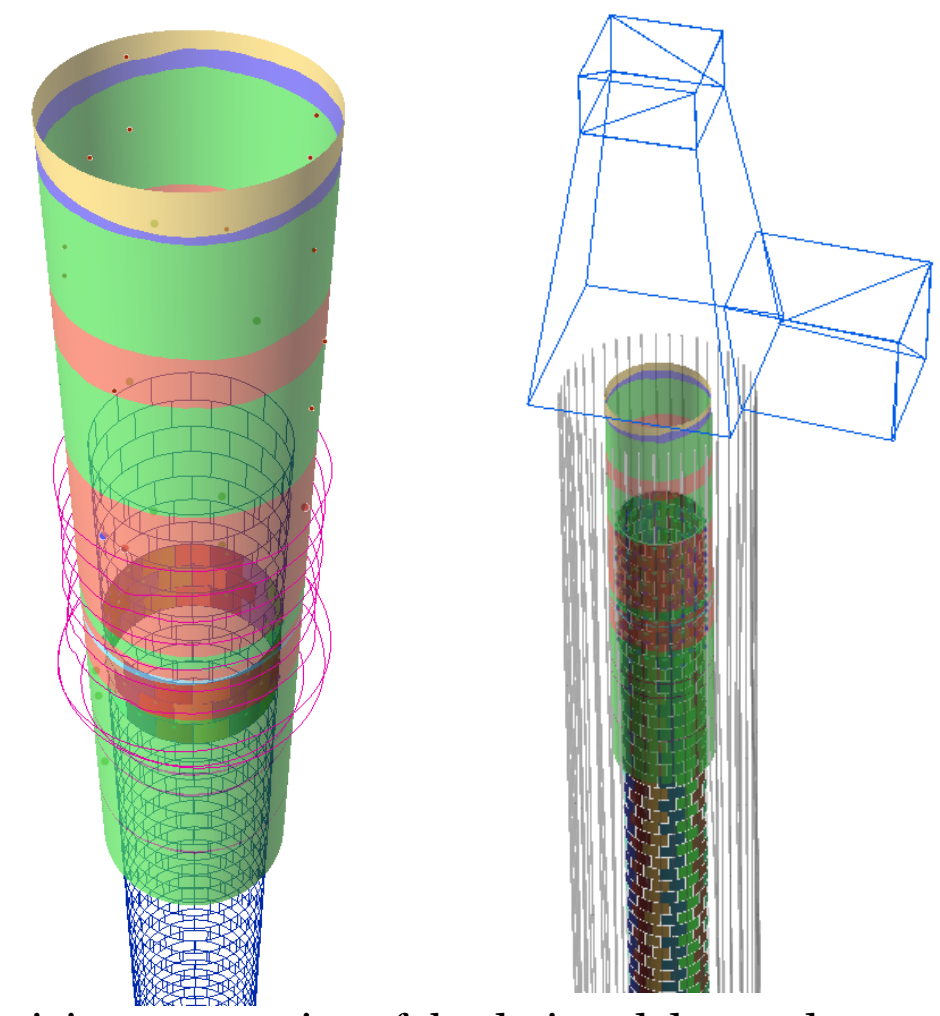

Fig. 9 The joint presentation of the designed data and executive survey

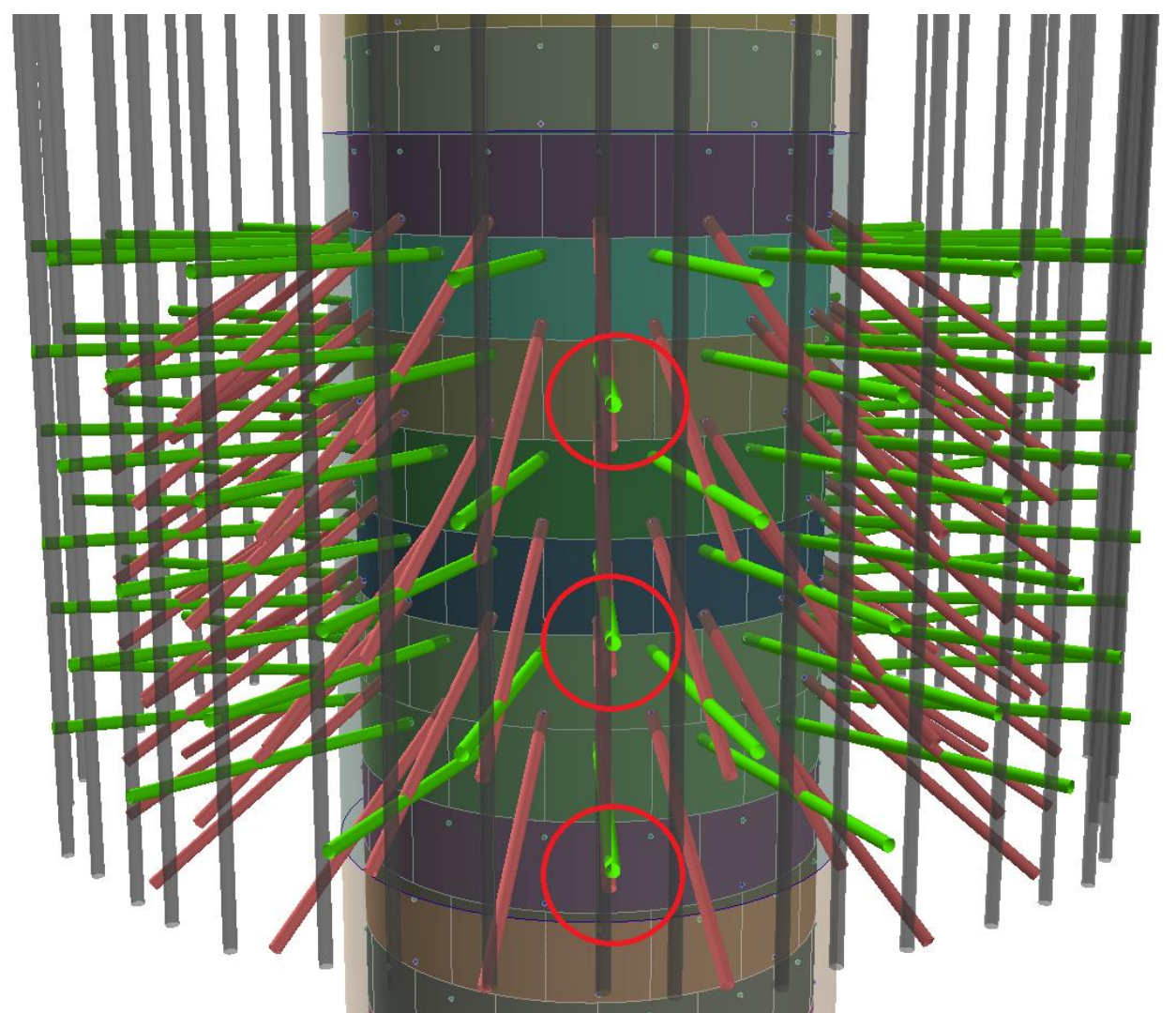

Fig.10. 3D visualization of tamponages curtain wells

In addition to visualizing 3D geometry, the ArcScene tool makes possible to create animations of high quality both in view and in the timeline mode (Fig. 11. Fig.12.). One more advantage of using this software product is its openness and interoperability with other software products. Thus, using CAD tools (Autocad Autodesk), 3D geometry of the mine shaft connection 
places with the transport, ventilation horizons and the cleaning of the sump (Fig. 11 of the interface) was obtained.

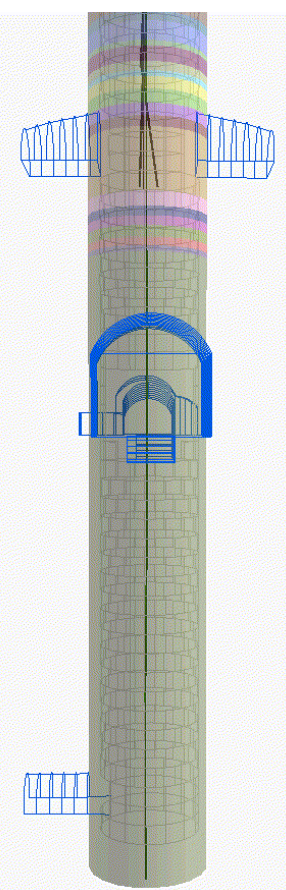

Fig. 11. 3D geometry of the mine shaft connection places with the transport, ventilation horizons and the cleaning of the sump

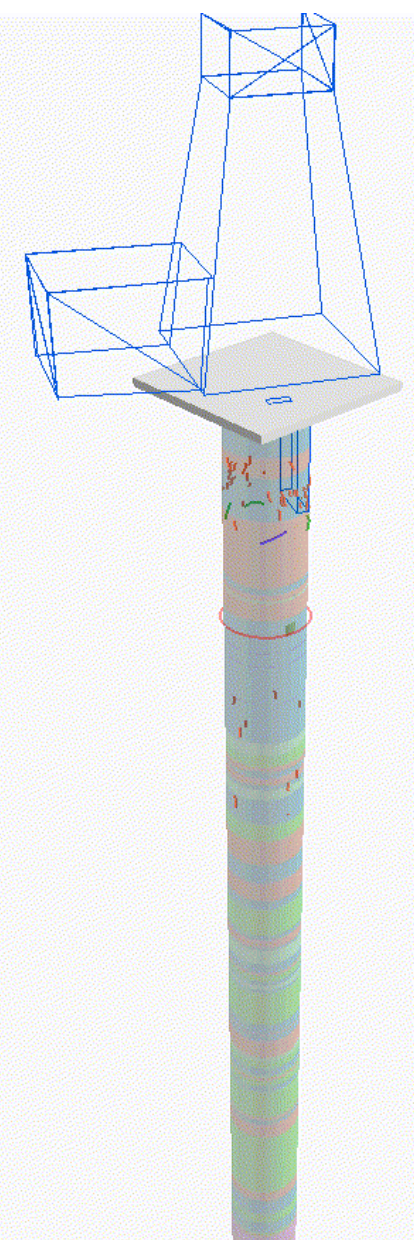

Fig. 12. An animation in the timeline mode characterizing the order of the tubing installation into the tubing rings 
Figure 12 shows an animation in the timeline mode characterizing the order of the tubing installation into the tubing rings. It should be noted that the first 10 rings are installed from bottom to top, that is, $10-9$ - 8, etc., and then top to bottom $11-12-13$, etc.

The author considers the analytical information system of sinking a shaft is necessary to be supplemented with photographic materials. The use of photographs, but not only sketches, spatially tied to the reamer and visualized in a $3 \mathrm{D}$ form may remove questions about the sketches quality, the exact location of cracks, water occurrence, etc.

\section{Conclusion}

The application of the given approach to the simulation of the "Mine Shaft - Geological Environment" system makes possible to obtain the information about the mass of rocks in the fixed space and combine it with the structural characteristics of the construction (Fig. 13).
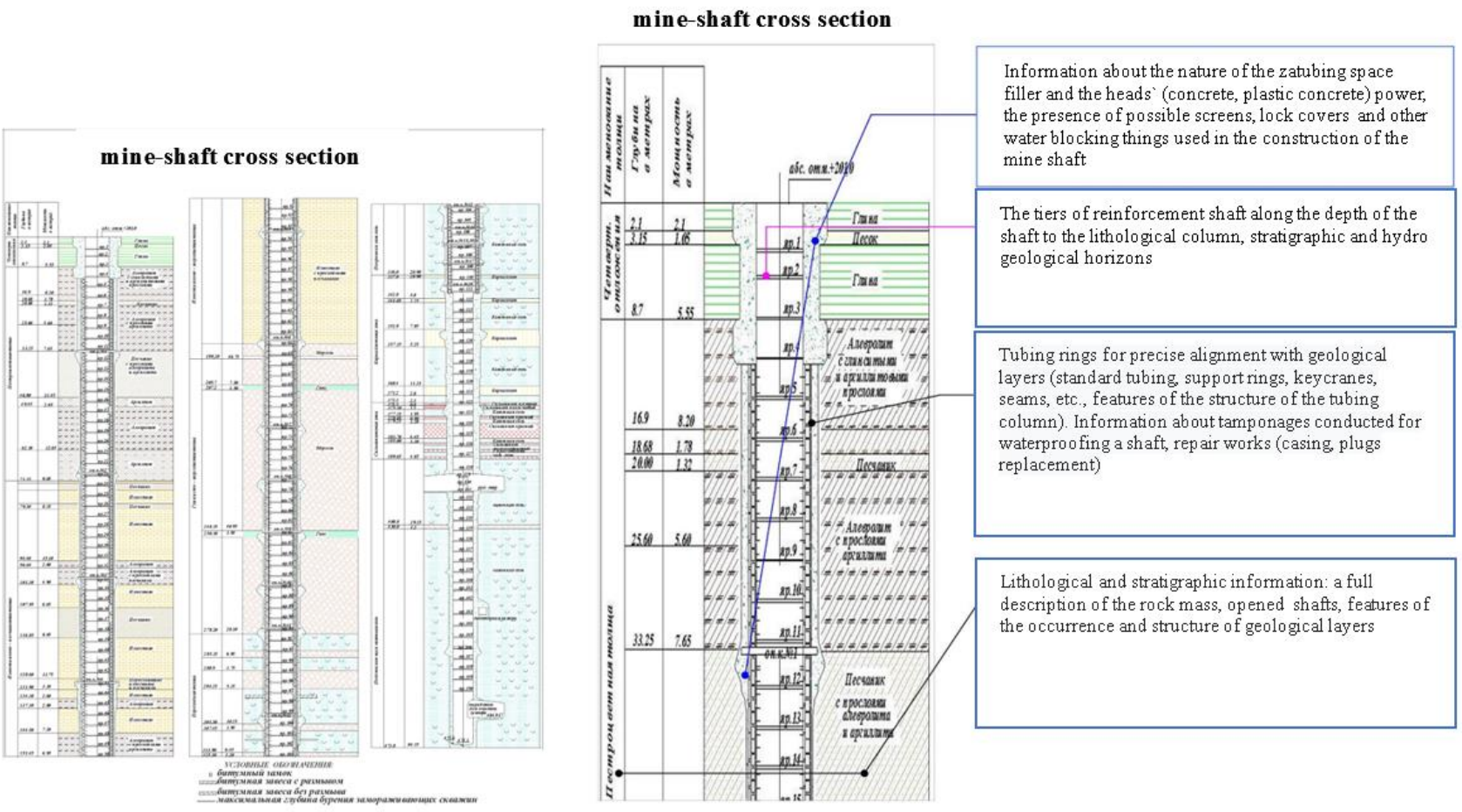

Fig.13. The joint presentation of the data in the system

"Geological Environment - Construction"

The technical and methodological solutions for the data grouping by the two-component natural-technical system "Geological Environment - Construction" by means of geoinformation technologies give the possibility of accumulating, structuring and making access to the heterogeneous data to each specialist of the enterprise.

The developed technical solutions provide effective processing, synthesis and visualization of data at a fundamentally new qualitative level.

The analytical information system created by the author will provide technical services specialists of the mining enterprise and related research and design organizations with reliable and efficient information at all stages of the construction life cycle.

This methodological approach to the geological engineering modeling of the system "Mine Shaft - Geological Environment" is analogous to the BIM modeling and is able to reduce the risk of emergencies in the course of sinking mine shafts as well as during their operation.

The application of the ArcGis software product makes possible both to conduct a spatial analysis of the available data and to prepare presentation material in a dynamic form (animation). The $3 \mathrm{D}$ visualization of the design and actual data is a means of additional control of geological mining information entered into the systems and the design decisions adopted. 


\section{References}

1. Savin I.I. Experimental and analytical method for calculating lining according to the results of measurements of normal tangential stresses // Study of the problems of mechanics of underground structures, Tula, 1987, p.31-34.

2. Tarasov V.V., Pestrikova V.S. Overview of emergencies that occurred at the Verkhnekamsk potash deposit during shaft shafting // Mining Information and Analytical Bulletin (scientific and technical journal). - 2015. - No.5. - S. 23-29.

3. Kashnikov A.V. Information-analytical system "trunk passport" for engineering and technical workers of mines // Strategy and processes of development of georesources. - Perm: Mining Institute of the Ural Branch of the Russian Academy of Sciences, 2011. - S. 251-252.

4. Mineshaft construction // Sight Power URL: http://sightpower.com/solutions/mineshaft-construction (accessed: 07/11/2019).

5. Tunneling of vertical shaft shafts // Russian Mining Portal URL: http://www.miningexpo.ru/useful/4927 (accessed: 07/11/2019).

6. Information-analytical system "Trunk passport" // Federal State Budgetary Institution Mining Institute Ural Run URL: http://www.mi-perm.ru/solution/nr?show_id=17 (accessed: 07/11/2019).

7. Konoplev A.V., Krasilnikov P.A. A technique for mapping territorial combinations of natural resources and their comprehensive assessment by a GIS technology (as exemplified by Perm krai) // Geography and Natural Resources. 2012. -Vol. 33, p 83-86. DOI: 10.1134 / S1875372812010131

8. Geoinformation support of the engineering-geological and geo ecological safety system of the city of Perm / Konoplev A.V., Kopylov I.S., Krasilnikov P.A., Kustov I.V. // Geoinformation support for the spatial development of the Perm Territory: Sat. scientific tr - Perm: Perm State National Research University, GIS Center, Perm State Scientific Research University. 2014. - S. 56-78

9. Khronusov V. V., Barskiy M. G., Krasilnikov P. A. Engineering geology software database for urban areas // International Multidisciplinary Scientific Geo Conference Surveying Geology and Mining Ecology Management, SGEM. 2018. -Vol. 18 (2.2), p. 163-170. DOI: 10.5593 / sgem2018 / 2.2 / So8.021

10. Three dimensional visualization and analysis of the results of engineering-geological and geo ecological studies / Kanya E.V., Dimuhametov D.M., Konoplev A.V., Spassky B.A., Lunev B.S. // Basic research. - 2014. - No. 9-12. - S. 2708-2712; URL: http://www.fundamental-research.ru/ru/article/view?id $=35420$ (date of access: 09.10.2019).

11. Pikulik EA, Mironov O.K. Data visualization in the process of engineering-geological research // Sergeevskie read. The role of engineering geology and research at the pre-design stages of construction development of territories: Mater. Session of the Scientific Council of the Russian Academy of Sciences on the problems of geoecology, engineering geology and hydrogeology. RAS Publishing House, Moscow. 2012.S. 73-78.

12. Jia W., Wang G. Multiple level prospectivity mapping based on $3 \mathrm{D}$ GIS and multiple geo science dataset analysis: a case study in Luanchuan $\mathrm{Pb}-\mathrm{Zn}$ district, China // Arabian Journal of Geosciences. -2019. - Vol. 12 (11). -P.332

13. Nugraha, R.P., O'Sullivan, J. A key process of natural state modeling: 3D Geological model of Jaboi Geothermal field, Nangro Aceh Darussalam, Indonesia // IOP Conference Series: Earth and Environmental Science. -2019. -Vol. -254 (1) N 012024 